\title{
Metrics for Bridge Resilience Indicators
}

\author{
Zehra Irem Turksezer \\ Department of Architecture, Built Environment and Construction Engineering, Politecnico di Milano, Italy. E- \\ mail: zehrairem.turksezer@polimi.it
}

\author{
Maria Pina Limongelli \\ Department of Architecture, Built Environment and Construction Engineering, Politecnico di Milano, Italy. E- \\ mail: mariagiuseppina.limongelli@polimi.it
}

\author{
Michael Havbro Faber \\ Department of Built Environment, Aalborg University, Denmark.E-mail: mfn@build.aau.dk
}

\begin{abstract}
Numerous past events have shown that natural and anthropogenic hazards have the potential to cause significant societal losses through damages to infrastructure systems and associated disruptions of societal functionalities. Examples hereof count the hurricanes Katrina and Rita in the USA, the attack on the Old Mostar bridge in Bosnia and Herzegovina during the Balkan war and the failure of the Morandi bridge in Italy. The degree to which such events impose consequences and impair or reduce societal service provisions is commonly assessed through the concept of resilience. Societal resilience may be significantly supported by safe, sustainable, and resilient infrastructure systems.

Several studies have been undertaken by researchers with regards to the concept of resilience management to enhance decisions on the infrastructural systems. An indicator-based framework has been presented in reference (Turksezer, Limongelli, and Faber 2020) to provide a tool to assist the decision maker in service life management of infrastructure resilience. In principle, using this framework, the decision maker may estimate the resilience of the system through observable characteristics (resilience indicators) and assess the efficiency of different design or intervention measures. This paper aims to propose a number of metrics for the resilience indicators that can facilitate the practical implementation of the framework.

Keywords: Resilience indicators, resilience management, decision analysis, information management
\end{abstract}

\section{Introduction}

Sustainable societal development critically depends on resilient and reliable infrastructure systems. Extreme events, whether natural or anthropogenic, may cause severe damages and lead to substantial reductions in infrastructure services. To manage infrastructure systems with respect to such events the concept of resilience has been introduced, see e.g. (Gardoni 2019) for a comprehensive overview and references to further literature.

The resilience of a system depends on a number of factors, including the degree to which the system is able to i) observe and appreciate that a potential disturbance is emerging, ii) mobilize adequate and sufficient resources to respond and iii) adapt strategies for management to new information at any time when such is made available over the course of the service of the system. To be able to inform decisions for optimal strategic, operational and tactical resilience management in a timely manner it is necessary that the relevant information is observed and processed consistently and efficiently. Indicators of resilience are tools to transfer to decision makers information regarding observable characteristics of the system, that affect resilience, in order to support and facilitate the decisionmaking process. The present contribution is the first attempt of the authors to define such observable characteristics of resilience indicators that can be used for their quantification. These characteristics will be addressed as 'subindicators'. Following the framework proposed in (Turksezer, Limongelli, and Faber 2020) the bridge system is structured into three subsystems (i.e. physical, information and organizational), each of them described by four main indicators (i.e. resistance, ductility, redundancy and diversity). Herein the sub-indicators for each of the three sub-systems and each of the four indicators will be introduced.

In Section 2, we address resilience management as a decision problem inspired by the Joint Committee on Structural Safety (JCSS 2008) risk-based approach. In Section 3 we 
introduce the observable system characteristics (sub-indicators) and finally Section 4 provides suggestions for further research.

\section{Resilience Management}

Most often resilience management is referred as the short-term ability of the system to recover from any disturbance event in a short time without any significant functionality loss. However, resilient system must be responsible not only from loss of functionality (or recovery) but also from the generation of the capacity which is crucial for the adaptation, efficient reorganization and recovery after disturbance events (Faber et al. 2017). This capacity must be valid for lifetime management of the system.

Resilience management can be addressed as governance of the system based on the ranking of decision alternatives through the identification, organization and communication of optimal actions to be undertaken on the system constituents during the life cycle of the system. Observed and assessed information on the state of the system supports decision makers on optimal actions for design and interventions in three-time horizons, i.e. before, during and after a disturbance event.

In any decision analysis for the management of systems, the first step is to identify the system. A systematic approach addressing infrastructure systems has been considered previously (Turksezer, Limongelli, and Faber 2020) with special focus on aspects relating to the resilience performances of the system.

Functionalities of critical infrastructure are clustered into three subsystems, i.e. physical, information and organizational. Subsystems consist of one or more interdependent constituents and each subsystem is a constituent of the main system. The physical subsystem must enable the system to achieve its design objectives (e.g. transportation infrastructure provides transportation for individuals and goods) with an adequate level of safety and reliability (e.g. any structure provides load carrying capacity). The functionality of the information subsystem is to transform into human knowledge what can be observed in the real-world (i.e. evidence), and to enable the flow of information between stakeholders within the system, in support to decision making. The management of the entire system is ensured by the organizational subsystem. The three subsystems are interrelated and connected through the flow of information provided by the information subsystem.

\subsection{Resilience indicators}

Resilience indicators are tools which are used to transmit specific information to the decision makers on any observable or measurable characteristic of the system or its constituents (i.e. subsystems). For each of the three subsystems (physical, information and organizational) defined in (Turksezer, Limongelli, and Faber 2020), seven resilience indicators were defined to describe the sub-system characteristics that describe resilience. and four of them are 'main' indicators (resistance, diversity, ductility and redundancy) which affect the other system characteristics more frequently used to define risk and functionality.

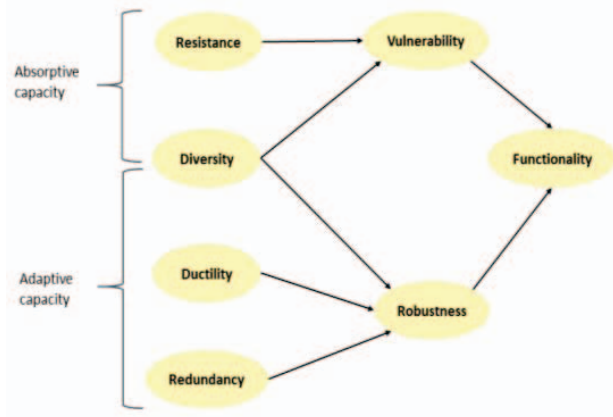

Fig. 1 Indicators at subsystem levels.

Figure 1 illustrates subsystem level indicators and their connections with a change with respect to the description given in the previous study. Here diversity contributes to both vulnerability and robustness. This is considered more consistent with the meaning of diversity indicator that describes the ability of the system to decrease the causes of failures (of different constituents). In Section 3 the system characteristics that contribute to each of the four main indicators will be listed and discussed.

In Figure 1, 4 main indicators are clustered into two groups that describe the two system capacities overcome the disturbance event: absorptive and adaptive capacities. Both capacities are considered in different time scales (i.e. building the capacity in the before phase, employing it in the during event phase, adjusting new capacity in the after-event phase). Absorptive 
capacity is the capability of the system (or its constituents) to absorb adverse impacts while adaptive capacity is the capability to adjust to overcome changing conditions in the system. Adaptive system can change in response to adverse impacts if absorptive capacity has been exceeded (Francis and Bekera 2014).

Figure 2 indicates, with reference to one of the system characteristics that affects resilience (that is resistance), the connection between the indicator and the decisions (red squares) made by the decision maker. These decisions are relevant to both monitoring of the indicator and adaptation of the system needed to manage the system resilience. The costs of the actions are indicated as well in the figure.

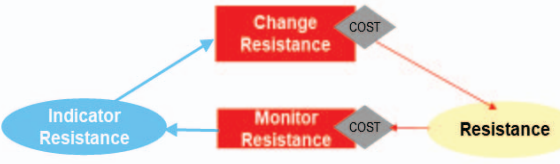

Fig. 1 Indicators as decision support.

\subsection{The three time-horizons of resilience management}

The general framework for resilience management presented in reference (Turksezer, Limongelli, and Faber 2020) did not address the time horizon and phases of resilience management. Inspired by the approach proposed in (JCSS 2008) we consider resilience management as a process structured into three phases (before, during and after a disturbance event).

There are three event phases defined in (JCSS 2008) and described here as:

i. The 'before' event phase starts from the day the system is commenced and ends when a disturbance event is appreciated.

ii. The 'during' event phase starts at the end of the before phase and ends at the end of the recovery, when the system starts to provide all services at the intended level.

iii. The 'after' event phase starts from the end of the during phase and lasts until a new event occurs. This phase coincides with the 'before' phase of the subsequent disturbance event. However, decisions in the after-event phase may account for any information and knowledge gained from the past disturbance events.

The definition of these three phases is aimed to describe a process for resilience management where information is used to support decisions. However, the transition between the 'before' and the 'during' phases is affected by a high level of uncertainty that depends on our knowledge about the disturbance event and on the information, that can be collected on the system and appreciated by stakeholders.

For example, the occurrence of a seismic shock is usually attributed to a sudden release of accumulated strain energy. According to the previous definition, the 'before' phase starts when the deformation of the earth crust begins, which means immediately after the occurrence of the previous seismic event and can last several years. However, usually this information is not available, and we tend to say that the 'before' phase ends when the first seismic shock happens. The physics behind a volcanic eruption and our knowledge about it is similar to that of an earthquake. Yet, a volcanic eruption is usually preceded by a modest seismic activity which provides an alert about the imminent disturbance event. Similarly, for the case of a seismic event there are phenomena, micro seismic shocks, that can be used to infer the occurrence of an earthquake or measures, such as the arrival of a faster seismic waves ( $P$ waves) that enable to profile the earthquake thereby supporting alert systems. The main difference between the two types of disturbance events (earthquakes and volcanic eruption) is the time available between the moment we acquire the information and the moment the disturbance event occurs.

Another example is related to the disturbance event caused by corrosion. This phenomenon develops over a relatively long period of time until the first crack forms and this can happen after some years from the start of corrosion. The difference with respect to the previous two events is that, in this case, there are tools to acquire information about the development of the phenomenon and this facilitates interventions.

The previous examples show that duration of the three phases depends on the characteristics of the disturbance event that affect the moment when information about its development become available to the decision maker. 
There are four types of disturbance events defined by (Faber, 2019) and exemplified by (Nielsen et al. 2019) for information channels;

1) The rare ones with large scale and high consequences, e.g. geohazards (earthquake, flood, etc.) and technical failures of technological information carriers within systems (power plants, wind turbine farms, etc.). These events build up for some decades, generate sudden losses and recovery may take some years.

2) Events that are more frequent in time with relatively small consequences that are commonly overseen and collectively ignored. Over adequate scales in time and space, they can lead to devastating consequences and their cumulative effects may trigger catastrophic consequences. Emissions to the environment, inadequate regulation and human errors as well as delayed information transfer due to organizational inadequacy and small biases in information management can be given as examples to this hazard type. These events may have a short 'before' phase but a long 'during' phase if they lead to Type 3 hazards.

3) Very rare, unpredictable, occurring over large extents in time and space and for which no knowledge is available. Examples are great volcanic eruptions, global climate change, satellite and electric communication losses due to solar storms, etc. The 'before' event phase may be protracted as well as the 'during' event phase, in case of extensive losses.

4) Disturbance events triggered by manipulated or neglected information as well as censored and erroneous observations. This kind of hazard can increase the extent of the Type 1-2-3 disturbance events. The 'before' event phase extends due to the lack of information (or neglecting) and more severe losses are experienced. Therefore, the duration of 'during' event phase takes longer than Type 1-2-3 disturbance events.
Decision making in each phase is supported by the information provided by the indicators. In each of the three phases the same indicators describe the system characteristics but the information on the system characteristics differs (e.g. resistance: design load capacity in the before event phase and residual load capacity in the during event phase, due to the demand generated by the exposure).

\section{Metrics for the Quantification of Resilience Indicators}

In this section for the each four main resilience indicators, recalled in Section 2.1., a list of observable system characteristics (sub-indicators) is given for each subsystem and for before and after event phases described in Section 2.2. The sub-indicators of the 'after' event phase coincide with those of the 'before' phase but they also contain the 'lesson learnt' that are changed, updated, or restored by utilizing the information collected in the other event phases.

The sub-indicators are proxy attributes (used when it is difficult to identify the value of an indicator directly) to measure the level of the related indicator.

The definition of the sub-indicators is meant to provide metrics for the quantification of resilience in the future developments of this research.

Resilience is an inter-disciplinary and intersectoral topic on which a vast body of literature exists, and many definitions of indicator metrics have been proposed. A comprehensive literature review was performed in the Web of Science database on engineering, community, and system resilience. The indicators and metrics proposed in literature are generally defined for the single subsystem (e.g. physical, information, organizational, etc.) or separately for each single event phase, with a clear prevalence of metrics defined for the recovery phase. At our best knowledge the definition of resilience metrics at subsystem level, for different event phases has not been proposed previously.

The question to which Table 1 attempts to answer is the following: 'Which information can be observed on a specific subsystem (for bridges) and on that subsystem's characteristics?'. 
Table 1 Definition and sub-indicators of four subsystem level indicators in before and during event phases.

\begin{tabular}{|c|c|c|c|}
\hline Indicators & Subsystems & Sub-indicators in before event phase & Sub-indicators in during event phase \\
\hline \multirow{3}{*}{$\begin{array}{c}\text { Resistance: } \\
\text { The highest } \\
\text { demand the } \\
\text { system can } \\
\text { meet. }\end{array}$} & $\begin{array}{c}\text { Physical } \\
\text { subsystem }\end{array}$ & $\begin{array}{l}\quad \text { Standards } \\
\text { - Design characteristics (target design } \\
\text { reliability, structural type and scheme, } \\
\text { geometry, material characteristics, demand } \\
\text { at the time of the design, available } \\
\text { standards/codes) } \\
\text { - Design load capacity } \\
\text { - Traffic capacity of the link/network } \\
\text { - Material durability } \\
\text { - Durability of network } \\
\quad \text { - Condition } \\
\text { - Age of the structure } \\
\text { - Degradation of transportation network } \\
\text { - Remaining lifetime } \\
\text { - Condition/status of a constituent } \\
\text { - Increased capacity of a structural } \\
\text { constituent by protective measures } \\
\text { - Increased capacity of a structural } \\
\text { constituent by periodic maintenance or } \\
\text { repair } \\
\text { - Survival to extreme loads in the past } \\
\text { - Stability/instability of the } \\
\text { structure/network }\end{array}$ & $\begin{array}{l}\text { - Number of failed/damaged } \\
\text { constituents on structure/in network (i.e. } \\
\text { extent of damage) } \\
\text { - Number of undamaged constituents (at } \\
\text { structural and network level) } \\
\text { - Number of repaired constituents } \\
\text { - Residual capacity of the structure / of } \\
\text { the network } \\
\text { - Capacity after recovery in structural } \\
\text { constituents/network }\end{array}$ \\
\hline & $\begin{array}{l}\text { Information } \\
\text { subsystem }\end{array}$ & $\begin{array}{l}\quad \text { Standards } \\
\text { - Number of data collection tools } \\
\text { - Load carrying capacity of technological } \\
\text { constituents } \\
\text { - Design strength of technological } \\
\text { constituents } \\
\text { - Security level of the network (against } \\
\text { specific extreme events, e.g. cyber-attacks, } \\
\text { solar storms, etc) } \\
\text { - Durability of constituents } \\
\text { - Demand at the time of the design } \\
\text { Technological development level at the } \\
\text { time of the design } \\
\quad \text { Condition } \\
\text { - Age of technological devices } \\
\text {-Degradation of information network } \\
\text {-Condition/status of constituents } \\
\text {-Increased capacity by protective measures } \\
\text { on technological constituents } \\
\text { - Stability of the network } \\
\text { - Survival to extreme events in the past }\end{array}$ & $\begin{array}{l}\text { - Number of failed/damaged } \\
\text { constituents (i.e. extent of damage) } \\
\text { - Number of undamaged constituents } \\
\text {-Decrease in the amount of information } \\
\text { and in the information flow } \\
\text { - Number of repaired constituents } \\
\text { - Capacity after recovery in } \\
\text { constituents/network } \\
\text { - Residual capacity of technological } \\
\text { constituents/network } \\
\text { - Amount of increased information on } \\
\text { the system } \\
\text { - Amount of lost knowledge of people } \\
\text { on construction techniques, } \\
\text { craftsmanship and building technology } \\
\text { due to loss of lives }\end{array}$ \\
\hline & $\begin{array}{l}\text { Organizational } \\
\text { subsystem }\end{array}$ & $\begin{array}{l}\quad \text { • Standards } \\
\text { - Capacity of governance (i.e. health status, } \\
\text { age, educational level, culture) } \\
\text { - Amount of financial resources (i.e. } \\
\text { wealth generation, capitals/investments) } \\
\text { - Maturity of organizational levels } \\
\text { - Durability of all resources } \\
\text { - Capacity of community (i.e. age, gender, } \\
\text { race, class, expertise) } \\
\text { - The quality of governance (i.e. } \\
\text { leadership, responsibilities of hierarchal } \\
\text { levels) } \\
\text { - Security of individuals (life safety) } \\
\quad \text { - Condition } \\
\text { - Degradation of physical resources } \\
\text { - Degradation of financial resources (i.e. } \\
\text { devaluation) }\end{array}$ & $\begin{array}{l}\text { - Amount of lost human, physical and } \\
\text { financial resources (i.e. extent of } \\
\text { damage) } \\
\text { - Amount of undamaged resources } \\
\text { - Residual capacity of human resources } \\
\text { (e.g. lower performance, health } \\
\text { problems) } \\
\text { - Amount of restored/recovered } \\
\text { resources }\end{array}$ \\
\hline
\end{tabular}




\begin{tabular}{|c|c|c|c|}
\hline & & $\begin{array}{l}\text { - Condition of all resources and } \\
\text { organizational levels } \\
\text { - Increased capacity of human by } \\
\text { formalized education and training in the } \\
\text { relevant topic } \\
\text { - Presence of social cohesion in } \\
\text { community } \\
\text { - Increased capacity and strength of } \\
\text { physical resources by scientific and } \\
\text { technological developments } \\
\text { - Stability of the network }\end{array}$ & \\
\hline \multirow{3}{*}{$\begin{array}{l}\text { Ductility: } \\
\text { The ability } \\
\text { of a system } \\
\text { or its } \\
\text { constituents } \\
\text { to maintain } \\
\text { some degree } \\
\text { of } \\
\text { functionality } \\
\text { or service } \\
\text { after one or } \\
\text { more of its } \\
\text { capacities } \\
\text { have been } \\
\text { exceeded. }\end{array}$} & $\begin{array}{c}\text { Physical } \\
\text { subsystem }\end{array}$ & $\begin{array}{l}\quad \bullet \quad \text { Standards } \\
\text { - Deformation capacity of material and } \\
\text { constituents } \\
\text { - Presence of interdependency in the } \\
\text { network } \\
\text { - Use of undesired network links (e.g. } \\
\text { using the roadway which is } 100 \mathrm{~km} \text { longer } \\
\text { than a bridge connection) }\end{array}$ & $\begin{array}{l}\text { - Maximum deformation of materials at } \\
\text { failure } \\
\text { - Presence of structural constituents with } \\
\text { brittle behaviour } \\
\text { - Residual ductility } \\
\text { - Elapsed time since the first constituent } \\
\text { loss }\end{array}$ \\
\hline & $\begin{array}{l}\text { Information } \\
\text { subsystem }\end{array}$ & $\begin{array}{l}\quad \text { Standards } \\
\text { - Deformation capacity of technological } \\
\text { constituents } \\
\text { - Presence of interdependency between } \\
\text { technological constituents } \\
\text { - Use of undesired technological } \\
\text { constituents }\end{array}$ & $\begin{array}{l}\text { - Continuous access to information } \\
\text { (including human knowledge) } \\
\text { - Presence of technological constituents } \\
\text { with brittle behaviour } \\
\text { - Amount of delay in information flow } \\
\text { - Elapsed time since the first constituent } \\
\text { loss }\end{array}$ \\
\hline & $\begin{array}{l}\text { Organizational } \\
\text { subsystem }\end{array}$ & $\begin{array}{l}\quad \text { Standards } \\
\text { - Undesired use of human resources for } \\
\text { replacement (e.g. calling retired personnel } \\
\text { to the duty or using people who have done } \\
\text { military service as first responders) } \\
\text { - Undesired use of financial resources for } \\
\text { replacement (e.g. presence of bank loan, } \\
\text { use the income of another infrastructure) } \\
\text { - Perseverance of human resources } \\
\text { - Continuity of leadership } \\
\text { - Presence of interdependency inside } \\
\text { hierarchical levels } \\
\text { - Presence of interdependent financial } \\
\text { resources }\end{array}$ & $\begin{array}{l}\text { - Coordination level in system, e.g. } \\
\text { participation of individuals to response, } \\
\text { social movements, staff engagement and } \\
\text { involvement } \\
\text { - Presence of physical resources (i.e. } \\
\text { human and materials) with brittle } \\
\text { behaviour } \\
\text { - Amount of time loss (for each actor) } \\
\text { - Elapsed time since the first constituent } \\
\text { loss } \\
\text { - Amount of sufficed (or insufficient) } \\
\text { budget (including external resources, } \\
\text { e.g. fund raising) }\end{array}$ \\
\hline \multirow{3}{*}{$\begin{array}{l}\text { Redundancy } \\
\text { : The ability } \\
\text { of a system } \\
\text { to } \\
\text { redistribute } \\
\text { demands } \\
\text { among } \\
\text { constituents } \\
\text { in given } \\
\text { damages } \\
\text { and failures. }\end{array}$} & $\begin{array}{l}\text { Physical } \\
\text { subsystem }\end{array}$ & $\begin{array}{l}\quad \bullet \quad \text { Interconnectivity } \\
\text { - Network connectivity } \\
\qquad \quad \text { Resourcefulness } \\
\text { - Number of alternative structural } \\
\text { constituents/materials } \\
\text { - Number of alternative constituents in } \\
\text { network (e.g. parallel bridges, or a bridge } \\
\text { and seaway) }\end{array}$ & $\begin{array}{l}\text { - Amount of utilized alternative } \\
\text { constituents (in structure or network) } \\
\text { - Amount of utilized alternative } \\
\text { materials } \\
\text { - Amount of lost or recovered structural } \\
\text { and non-structural constituents }\end{array}$ \\
\hline & $\begin{array}{l}\text { Information } \\
\text { subsystem }\end{array}$ & $\begin{array}{l}\qquad \quad \text { Interconnectivity } \\
\text { - Network connectivity (to provide } \\
\text { information flow) } \\
\qquad \quad \text { Resourcefulness } \\
\text { - Number of alternative information } \\
\text { acquisition tools } \\
\text { - Number of alternative channels to } \\
\text { support information flow between } \\
\text { subsystems } \\
\text { - Number of backup systems } \\
\text { - Amount of knowledge of people } \\
\text { living/working in the same place }\end{array}$ & $\begin{array}{l}\text { - Number of used alternative } \\
\text { communication channels } \\
\text { - Number of lost and recovered } \\
\text { alternative constituents } \\
\text { - Number of alternative scenarios and } \\
\text { plans put into practice (e.g. alternative } \\
\text { emergency management scenarios, } \\
\text { communication plans, etc.) } \\
\text { - Number of used backup systems }\end{array}$ \\
\hline & $\begin{array}{c}\text { Organizational } \\
\text { subsystem }\end{array}$ & $\begin{array}{c}\bullet \quad \text { Interconnectivity } \\
\text { - Connectivity between organizational } \\
\text { levels (interoperability) } \\
\text { - Resourcefulness }\end{array}$ & $\begin{array}{l}\text { - Used alternative human resources } \\
\text { (number of people/teams) for the same } \\
\text { duty } \\
\text { - Amount of distributed resources (in } \\
\text { terms of money) }\end{array}$ \\
\hline
\end{tabular}




\begin{tabular}{|c|c|c|c|}
\hline & & $\begin{array}{l}\text { - Number/presence of alternative } \\
\text { sites/areas for emergency management } \\
\text { service } \\
\text { - Number/presence of alternative models of } \\
\text { obtaining supplies/resources } \\
\text { - Number of alternative solutions for } \\
\text { emergency } \\
\text { - Number/presence of human resources } \\
\text { inside teams and management levels } \\
\text { - Presence of help of other communities }\end{array}$ & $\begin{array}{l}\text { - Amount (number or cost) of lost and } \\
\text { recovered alternative resources }\end{array}$ \\
\hline \multirow{3}{*}{$\begin{array}{l}\text { Diversity: } \\
\text { The ability } \\
\text { of the } \\
\text { system to } \\
\text { reduce the } \\
\text { likelihood of } \\
\text { common } \\
\text { cause } \\
\text { failures of } \\
\text { different } \\
\text { constituents } \\
\text { in the } \\
\text { system. }\end{array}$} & $\begin{array}{c}\text { Physical } \\
\text { subsystem }\end{array}$ & $\begin{array}{l}\quad \bullet \quad \text { Presence of variety } \\
\text {-Presence of different protective measures } \\
\text { (against different disturbance events) } \\
\text {-Number of different transport means in } \\
\text { the same network } \\
\text {-Presence of different constituents in the } \\
\text { network (e.g. different connectivity and } \\
\text { routes) } \\
\text { - Presence of different protection measures } \\
\bullet \quad \text { Substitutability } \\
\text { - Flexibility of material and constituent } \\
\text { selection }\end{array}$ & $\begin{array}{l}\text { - Number of used different constituents } \\
\text { (in structural and network level) } \\
\text { - Number of different materials used to } \\
\text { replace/rehabilitate constituents (in } \\
\text { structural and network level) } \\
\text { - Number of constituents that cannot be } \\
\text { recovered due to their irreplaceable } \\
\text { characteristics (i.e. unique materials) }\end{array}$ \\
\hline & $\begin{array}{c}\text { Information } \\
\text { subsystem }\end{array}$ & $\begin{array}{l}\quad \text { • Presence of variety } \\
\text {-Presence of different human knowledge } \\
\text { and memories } \\
\text {-Variety of plans and scenarios for } \\
\text { different disturbance events } \\
\text {-Presence of different technological } \\
\text { constituents (e.g. different backup systems, } \\
\text { information transferring channels and } \\
\text { acquisition tools, communication channels } \\
\text { etc.) } \\
\text {-Presence of different control and } \\
\text { monitoring systems } \\
\text { - Presence of different hardware and } \\
\text { software constituents } \\
\text { - Presence of different protection measures } \\
\quad \text { - Substitutability } \\
\text { - Flexibility of material and constituent } \\
\text { selection } \\
\text { - Presence of different alternative storage } \\
\text { for memories and legacy data }\end{array}$ & $\begin{array}{l}\text { - Amount of proxy information } \\
\text { - Used different scenarios, plans } \\
\text { - Used different technological } \\
\text { constituents } \\
\text { - Availability of separate backup on site } \\
\text { to not have interruption of information } \\
\text { flow } \\
\text { - Procuration of timely and relevant } \\
\text { information by different channels } \\
\text { - Lost and/or recovered different } \\
\text { technological constituents } \\
\text { - Variety of information that may affect } \\
\text { decision making (e.g. tsunami } \\
\text { probability in case of earthquake) } \\
\text { - Amount of different knowledge } \\
\text { (expertise) included in the information } \\
\text { flow (between decision makers) } \\
\text { - Used different information storage } \\
\text { (e.g. use of human knowledge and } \\
\text { archives in case of a cyber attack to } \\
\text { cloud storages) }\end{array}$ \\
\hline & $\begin{array}{c}\text { Organizational } \\
\text { subsystem }\end{array}$ & \begin{tabular}{l}
\multicolumn{1}{c}{$\quad$ Presence of variety } \\
-Number of different fund allocation \\
-Different levels of management (variety \\
of knowledge) \\
-Presence of different training and \\
education activities for different \\
disturbance events \\
-Amount of different physical resources \\
(e.g. technical equipment, vehicles etc.) \\
-Number of different personnel and \\
institutions \\
- Variety of demographic characteristics \\
(i.e. level of education, occupation, \\
ancestral) \\
$\quad$ Substitutability \\
- Flexibility of resources to take each \\
other's roles \\
-Amount of different resources (e.g. \\
stockpile) for customers/ users
\end{tabular} & $\begin{array}{l}\text { - Availability of different financial } \\
\text { resources (from different sources) } \\
\text { - Amount of lost and recovered different } \\
\text { resources } \\
\text { - Amount of different resources used in } \\
\text { the emergency } \\
\text { - Participation of different levels (e.g. } \\
\text { national, village, neighbour level) to } \\
\text { recovery activities }\end{array}$ \\
\hline
\end{tabular}


In the table each cell contains a metric that describes a specific system characteristic. The column of 'before' event phase describes characteristics designed, built, or kept functional before any disturbance event while the column of 'during' event phase relates to response, loss and recovery states of the specific subsystem.

A series of sub-indicators are listed in Table 1. It is not possible to collect information on each characteristic. Therefore, some sub-indicators are proposed to replace another if information is not available (e.g. number of undamaged constituents and number of repaired constituents).

Table 1 shows the decision maker where and which information to look for before making a decision in different time horizons: information about the past events enables decision maker to analyse the management past critically.

In the during event phase, some terms may look similar with before event phase indicators (e.g. load capacity), but the information transferred to decision maker is different (e.g. design load capacity in the before event phase and residual load capacity in the during event phase).

Herein, comprehensive, and generic bridge sub-indicators are described that can be adapted for different infrastructure systems.

\section{Conclusion}

In this paper the preliminary results of an investigation aimed to formulate resilience indicators, observable system characteristics (i.e. sub-indicators) and metrics for resilience management of bridge systems are presented. In the previous paper, the authors proposed a resilience management framework where the bridge system is represented as the integration of three subsystems (i.e. physical, information and organizational) providing different functionalities. Indicators and relevant metrics are defined in this paper to describe the characteristics of each subsystem and for three time horizons (before, during and after) that are assumed to characterize a disturbance event.

A comprehensive literature review has been carried out in several sectors and disciplines in order to identify commonalities and discrepancies between the existing metrics and consistently integrate them in the resilience management framework.

Apparently, many existing metrics and indicators with different names address similar or identical system characteristics and can be thus clustered under common definitions. In this perspective the indicators proposed in our framework constitute a promising starting point.

In the future research stages, this approach will be applied to all resilience indicators proposed in the previous paper. Thence a decision support tool in the context of resilience informed decision making will be formed to support asset managers.

\section{References}

Faber, M. H., J. Qin, S. Miraglia, and S. Thöns. 2017. "On the Probabilistic Characterization of Robustness and Resilience.” Procedia Engineering 198 (September 2016): 1070-83. https://doi.org/10.1016/j.proeng.2017.07.151.

Francis, Royce, and Behailu Bekera. 2014. "A Metric and Frameworks for Resilience Analysis of Engineered and Infrastructure Systems." Reliability Engineering and System Safety 121: 90-103. https://doi.org/10.1016/j.ress.2013.07.004.

Gardoni, P. 2019. Routledge Handbook of Sustainable and Resilient Infrastructure. Routledge International Handbooks. Routledge. https://books.google.it/books?id=z4sgtAEACAAJ.

JCSS. 2008. Risk Assessment in Engineering: Principles, System Representation \& Risk Criteria.

Nielsen, Linda, Sebastian Tølbøll Glavind, Jianjun Qin, and Michael H. Faber. 2019. "Faith and FakesDealing with Critical Information in Decision Analysis." Civil Engineering and Environmental Systems $\quad 36 \quad$ (1): $32-54$. https://doi.org/10.1080/10286608.2019.1615476.

Turksezer, Z.I., M.P. Limongelli, and M. H. Faber. 2020. "On a Generic Framework for Systems Resilience Modelling in the Context of Historical Bridges." Sustainable and Resilient Infrastructure (submitted). 